\title{
Dissecting the Role of Curcumin in Tumour Growth and Angiogenesis in Mouse Model of Human Breast Cancer
}

\author{
Sabrina Bimonte, ${ }^{1}$ Antonio Barbieri, ${ }^{2}$ Giuseppe Palma, ${ }^{2,3}$ Domenica Rea, ${ }^{1}$ \\ Antonio Luciano, ${ }^{1}$ Massimiliano D'Aiuto, ${ }^{4}$ Claudio Arra, ${ }^{2}$ and Francesco Izzo ${ }^{1}$ \\ ${ }^{1}$ Hepatobiliary Unit, Istituto Nazionale per la Studio e la Cura dei Tumori "Fondazione G. Pascale" (IRCCS), \\ Via Mariano Semmola, 80131 Naples, Italy \\ ${ }^{2}$ S.S.D. Sperimentazione Animale, Istituto Nazionale per lo Studio e la Cura dei Tumori "Fondazione G. Pascale" (IRCCS), \\ Via Mariano Semmola, 80131 Naples, Italy \\ ${ }^{3}$ Istituto di Endocrinologia e Oncologia Sperimentale del Consiglio Nazionale delle Ricerche c/o, Dipartimento di Biologia e Patologia \\ Cellulare e Molecolare "L. Califano", Università degli Studi di Napoli "Federico II", Via Pansini 5, 80131 Naples, Italy \\ ${ }^{4}$ Division of Breast Surgery, Department of Breast Disease, Istituto dei Tumori di Napoli "Fondazione G. Pascale" (IRCCS), \\ 80131 Naples, Italy
}

Correspondence should be addressed to Sabrina Bimonte; s.bimonte@istitutotumori.na.it

Received 21 October 2014; Revised 20 January 2015; Accepted 23 January 2015

Academic Editor: Anne Hamburger

Copyright (C) 2015 Sabrina Bimonte et al. This is an open access article distributed under the Creative Commons Attribution License, which permits unrestricted use, distribution, and reproduction in any medium, provided the original work is properly cited.

\begin{abstract}
Breast cancer is considered the most common cancer for women worldwide and it is now the second leading cause of cancer-related deaths among females in the world. Since breast cancer is highly resistant to chemotherapy, alternative anticancer strategies have been developed. In particular, many studies have demonstrated that curcumin, a derivative of turmeric, can be used as natural agent in treatment of some types of cancer by playing antiproliferative and antioxidant effects. In our study, we assessed the antitumor activities of curcumin in ER-negative human breast cancer cell line resistant to chemotherapy, MDA.MB231 by in vitro and in vivo experiments. In vitro data allowed us to demonstrate that curcumin played a role in regulation of proliferation and apoptosis in MDA.MB231 cells. In vivo, by generation of mouse model of breast cancer, we showed that treatment of curcumin inhibited tumor growth and angiogenesis. Specifically, we showed that curcumin is able to deregulate the expression of cyclin D1, PECAM-1, and p65, which are regulated by NF- $\kappa$ B. Our data demonstrated that curcumin could be used as an adjuvant agent to chemotherapy in treatment of triple negative breast cancer.
\end{abstract}

\section{Introduction}

Breast cancer is considered the most common cancer for women worldwide and it is now the second leading cause of cancer-related deaths among females in the world [1]. Since breast cancer is highly resistant to chemotherapy $[2,3]$ and in particular very limited treatment options exist for the ER-negative patients [4], alternative anticancer strategies are needed. Curcumin, which is extracted from the plant Curcuma longa, is such natural agent with anti-antitumor and anti-inflammatory effects. Several preclinical studies focused on the anticancer efficacy of curcumin have been tested in some cancer models including breast cancer [5].
Results from these studies reported that curcumin alone, in combination with targeted compounds or chemotherapeutic agents, is able to inhibit human cancer cell proliferation and tumorigenesis at different molecular levels [6-15]. Many studies have reported that curcumin inhibits human breast cancer cell growth by modulating the NF- $\kappa \mathrm{B}$ signaling pathway [11, 13, 16-20]. In addition, it has been showed that curcumin decreased human epidermal growth factor 2 (HER2) oncoprotein expression, the phosphorylation of Akt, MAPK, and the expression of NF- $\kappa \mathrm{B}$ in both BT474 and SK-BR-3-hr cells [21]. Interestingly, it has been found that curcumin suppressed breast tumor angiogenesis by abrogating osteopontin or medroxyprogesterone acetate 
induced VEGF expression [22, 23]. Moreover, it has been reported that the combination of epigallocatechin gallate (EGCG) and curcumin is efficacious in both in vitro and in vivo models of $\mathrm{ER} \alpha$-breast cancer by the regulation of VEGFR-1 expression [24]. The effects of curcumin have been also tested in MDA.MB231 cells by different groups [2532]. In our study, we dissected the role of curcumin on tumour growth and angiogenesis in mouse model of human breast cancer. We first demonstrated that curcumin, in vitro, has a role in the regulation of proliferation and apoptosis of MDA.MB231 cells. In vivo, we showed that curcumin inhibited tumor growth and angiogenesis in a heterotopic mouse model of breast cancer by influencing the expression of NF- $\kappa$ B-regulated gene products (cyclin D1, PECAM-1, and p65). Taken together, our data indicate that curcumin could be used as an adjuvant agent to chemotherapy in treatment of triple negative breast cancer.

\section{Material and Methods}

2.1. Reagents. Curcumin, used for in vitro experiments, was obtained from Sigma Aldrich (Piscataway, NJ) and was dissolved in dimethyl sulphoxide (DMSO) to a concentration of $500 \mu \mathrm{M}$ as a stock solution. It was diluted in DMEM and $10 \%$ FBS and added to MDA.MB231 cells in two different doses $(10$ and $50 \mu \mathrm{M})$. The following polyclonal antibodies against cyclin D1, and polyclonal antibodies against PECAM1, were obtained from Santa Cruz Biotechnology (Santa Cruz, CA). Anti-p65 antibody was kindly provided by Imgenex (San Diego, CA). The liquid DAB+ Substrate Chromogen System-HRP used for immunocytochemistry was obtained from DakoCytomation (Carpinteria, CA). Penicillin, streptomycin, RPMI 1640, and fetal bovine serum (FBS) were obtained from Invitrogen (Grand Island, NY). Tris, glycine, $\mathrm{NaCl}, \mathrm{SDS}$, and bovine serum albumin (BSA) were obtained from Sigma Chemical (St. Louis, MO). Complete feed for mice with curcumin $0,6 \%$ (AIN-93G) was purchased by Mucedola (Settimo Milanese, Italy).

2.2. Cell Lines and Mice. ER-negative breast cancer cell line MDA.MB231 was obtained from American Type Culture Collection (Manassas, VA). Cells were cultured in Dulbecco's Modified Eagle Medium (DMEM) supplemented with fetal bovine serum (FBS) 10\%, antibiotics (penicillin 100 units $/ \mathrm{mL}$, streptomycin $100 \mu \mathrm{g} / \mathrm{mL})$, and l-glutamine $(2 \mathrm{mM})$ at $37^{\circ} \mathrm{C}$ in atmosphere of $5 \%$ of $\mathrm{CO}_{2}$. Female Foxn $1^{\text {nu/nu }}$ mice (six to eight weeks old, Harlan, San Pietro al Natisone) were maintained under specific pathogen free (SPF) conditions.

\subsection{Proliferation Assay, Wound-Healing Assay, and In Vitro} Apoptosis. The effect of curcumin on cell proliferation was determined by using TACS 3-(4,5-dimethylthiazol-2-yl)2,5-diphenyltetrazolium bromide (MTT) cell proliferation assay (Trevigen, Gaithersburg) as previously described [15]. Wound-healing assay and in vitro apoptosis on MDA.MB231 cells were performed as previously described $[15,33]$.
2.4. NF- $\kappa B$ Activation in Cell and Tumor Samples. To assess $\mathrm{NF}-\kappa \mathrm{B}$ activation, we performed electrophoresis mobility shift assays (EMSA) as previously described [15, 33].

2.5. Western Blot Analysis. Breast tumor tissues (75$100 \mathrm{mg} / \mathrm{mouse}$ ) from control and mice treated with curcumin were minced and incubated on ice for $1 \mathrm{~h}$ in $0.5 \mathrm{~mL}$ of ice-cold Lysis Buffer (10 mM Tris, pH 8.0, $130 \mathrm{mM}$ Nail, 1\% Triton $\mathrm{X}-100,10 \mathrm{mM}$ NaF, $10 \mathrm{mM}$ sodium phosphate, $10 \mathrm{mM}$ sodium pyrophosphate, $2 \mu \mathrm{g} / \mathrm{mL}$ aprotinin, $2 \mu \mathrm{g} / \mathrm{mL}$ leupeptin, and $2 \mu \mathrm{g} / \mathrm{mL}$ pepstatin). The minced tissues were homogenized using a Dounce homogenizer and centrifuged at $16,000 \times \mathrm{g}$ at $4^{\circ} \mathrm{C}$ for $10 \mathrm{~min}$. Western blotting analysis was performed according to standard protocols. $\alpha$-actin and $\beta$-tubulin were used as loading control.

\subsection{Establishment of Subcutaneous Xenograft Breast Tumor} Model in Nude Mice. The nude mice were subcutaneously inoculated with cell suspension containing $2,5 \times 10^{6}$ MBA.MB231 cells into the right side flank area of mice. A total of 16 female Foxn $1^{\text {nu/nu }}$ mice were used in this experiment and maintained in a barrier facility on HEPAfiltered racks. The subcutaneous tumors were monitored and when the volume of tumors reached $\sim 30-60 \mathrm{~mm}^{3}$, mice were randomized into the following treatment groups $(n=2)$ : (a) 8 untreated mice placed in normal diet and (b) 8 mice treated with curcumin placed in diet containing curcumin at $0,6 \%$. Tumor volumes were monitored once a week by using a digital caliper. Therapy was continued for 6 weeks and animals were sacrificed at reaching of cut-off. Measured values were used to calculate the tumor volume according to the formula [length $(\mathrm{mm}) \times$ width $\left.(\mathrm{mm})^{2}\right] / 2$. In order to test microvessel formation on tumor tissues in mice, fluorescein-isothiocyanate- (FITC-) dextran $(100 \mu \mathrm{L})$ was injected into the tail veins of mice to visualize microvessels within $150 \mu \mathrm{m}$ (using single-photon microscopy) or $\sim 600 \mu \mathrm{m}$ (using multiphoton laser-scanning microscopy [MPLSM]) of a tumour/window interface. After sacrifice of mice, a portion of the tumor tissue was fixed in $10 \%$ formalin for histological analysis while the remaining tissue was stored at $-80^{\circ} \mathrm{C}$ for molecular studies. All the experiments performed on mice were in compliance with the guidelines for the Care and Use of Laboratory Animals of the National Cancer Institute, IRCCS, Fondazione Pascale.

2.7. Immunohistochemistry. Tumour samples from controls and treated-mice were embedded in paraffin and fixed with paraformaldehyde. After being washed in PBS, the slides were blocked with protein block solution (DakoCytomation) for $20 \mathrm{~min}$ and then incubated overnight with polyclonal antigoat PECAM-1 (1:100). After the incubation, the slides were washed and then incubated with biotinylated link universal antiserum followed by horseradish peroxidase-streptavidin conjugate (LSAB + kit). The slides were rinsed, and colour was developed using 3,3' -diaminobenzidine hydrochloride as a chromogen. Finally, sections were rinsed in distilled water, counterstained with haematoxylin, and mounted with DPX mounting medium for evaluation. Pictures were captured 


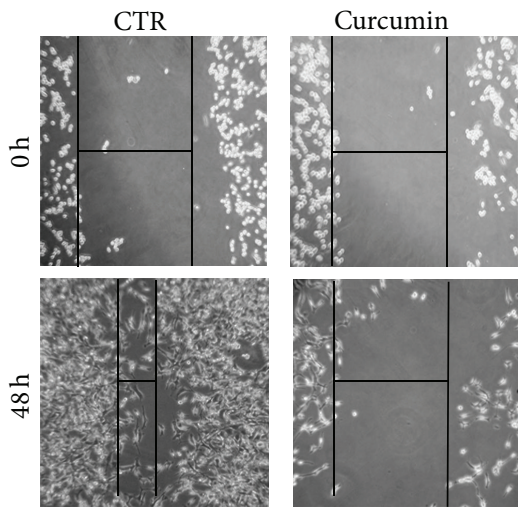

(a)

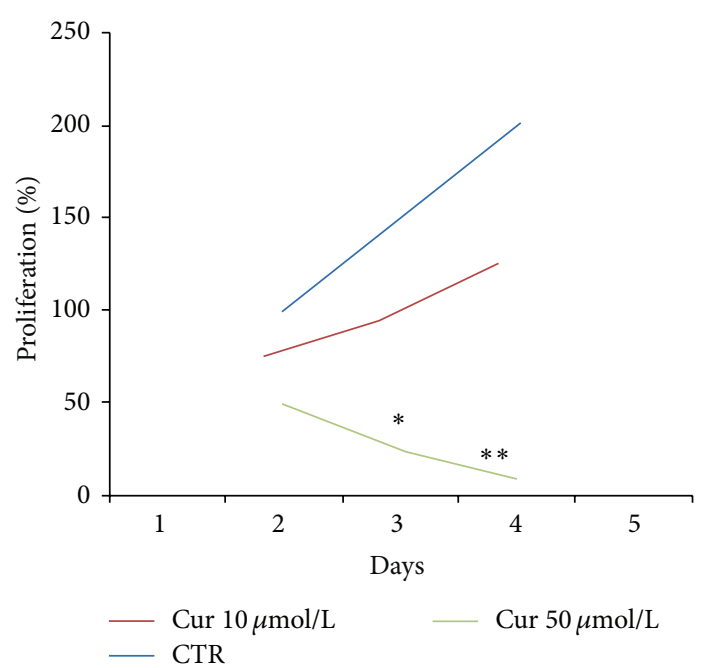

(c)

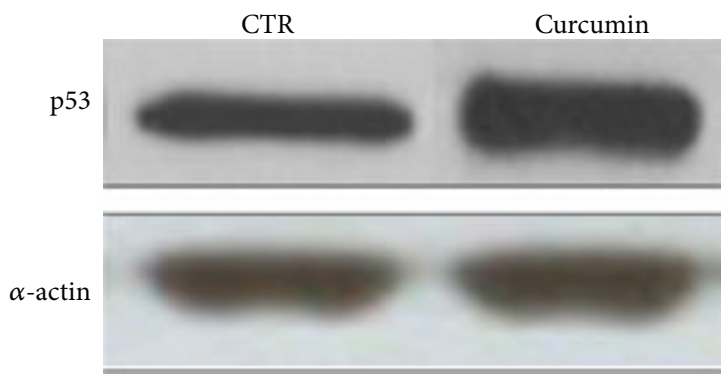

(e)

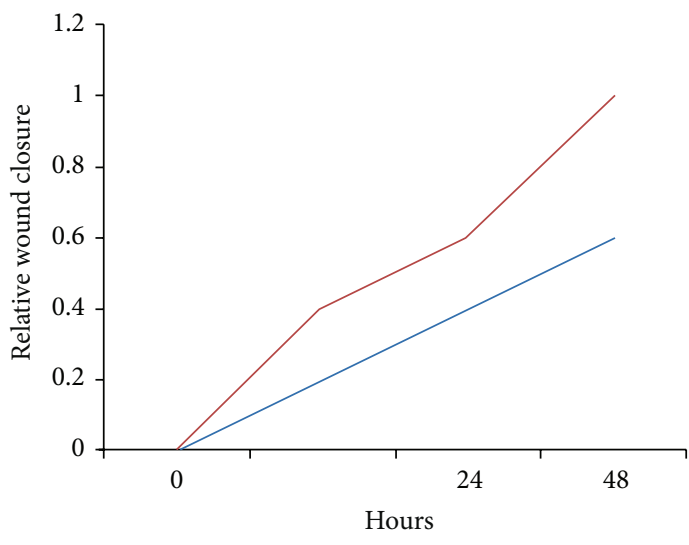

- CTR

— Curcumin

(b)

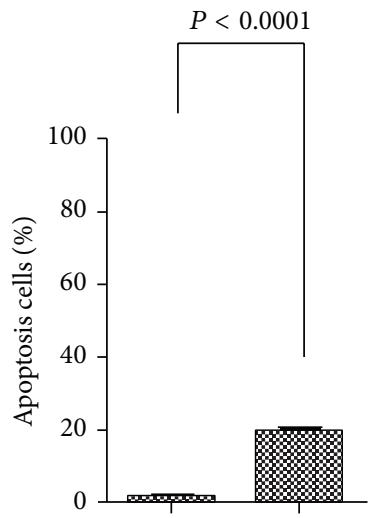

(d)

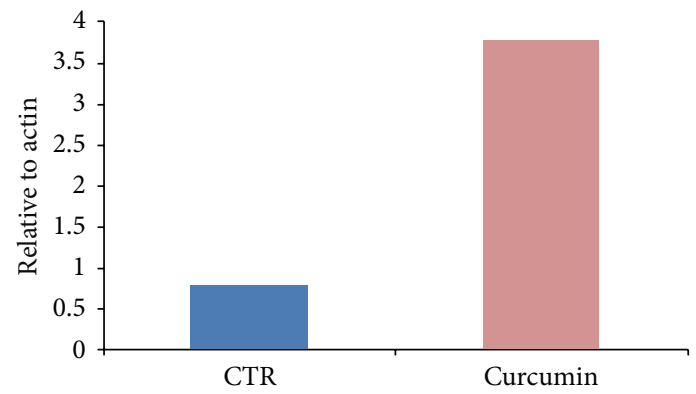

(f)

FIGURE 1: Curcumin inhibits proliferation and enhances apoptosis in MDA.MB231 cancer cells. (a) For wound-healing assay, MDA.MB231 cells were wounded by scratching and monitored over $48 \mathrm{~h}$ to determine the rate of wound closure (40x magnification), scale bar, $200 \mu \mathrm{m}$. (b) Cell migration was assessed by measuring relative wound closure. Data represent mean $\pm \operatorname{SEM}\left({ }^{* *} P<0.01\right.$; $\left.{ }^{*} P<0.05\right)$. At $48 \mathrm{~h}$ after wound induction, there were clearly less cells in the denuded area of curcumin treated cells than untreated cells. (c) MTT assay results show a suppression of proliferation in breast cancer cells treated with curcumin respect to control cells S.E. Data represent mean \pm SEM $\left({ }^{* *} P<0.01\right.$; $\left.{ }^{*} P<0.05\right)$. (d) In vitro apoptosis assay by flow cytometry indicated that curcumin $(10 \mu \mathrm{M})$ enhances apoptosis in MDA.MB231 cells $(P$ value $<0.0001)$. ((e)-(f)) Western blot showing that curcumin enhances the expression of p53 in MDA.MB231 cells treated with curcumin (lane 2) with respect to controls (lane 1). $\alpha$-actin was used as loading control. 


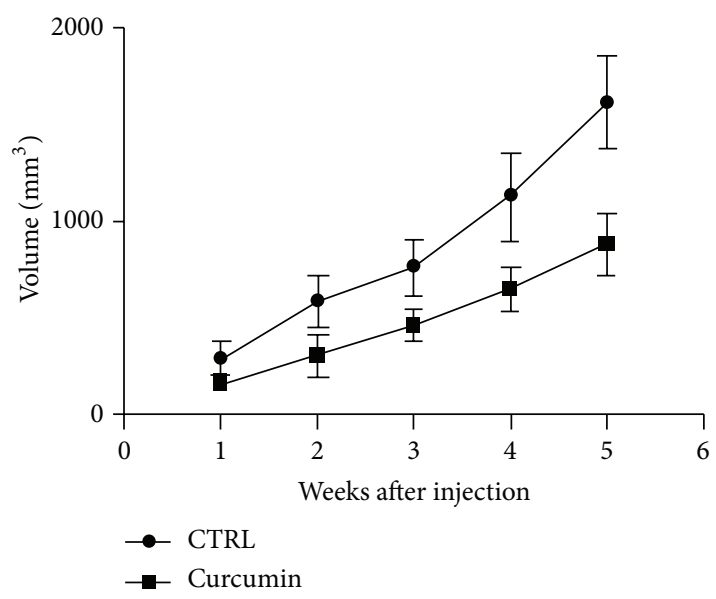

(a)

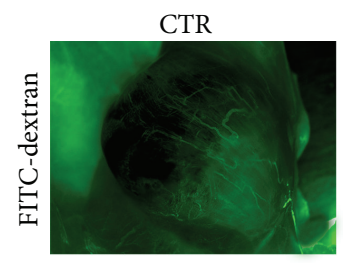

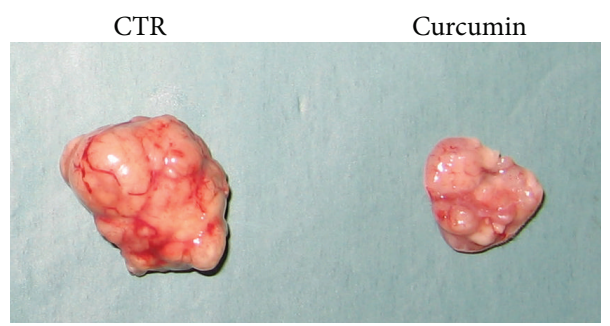

(b)

(c)

FIGURE 2: Curcumin inhibits the tumor growth in xenograft mouse model of breast cancer. (a) Curcumin inhibits tumor growth in breast tumor xenograft model. Breast tumor growth in 8 mice treated with vehicle $(\bullet)$ and 8 mice treated with curcumin ( $\square)$. Tumor volumes decreased significantly after 3 weeks of curcumin treatment until 6 weeks $(P=0.0195)$ as compared with control (vehicle-treated). (b) Ex vivo tumour from control (left) and treated mice (right). (c) Measurements of fluorescence per second depicting microvessel tumor (FITCDEXTRANE) using MacroFluo images showed that curcumin inhibits the angiogenesis in tumour of mice treated with curcumin (right) with respect to controls (left).

with a Photometric Cool SNAP CF colour camera (Nikon, Lewisville, TX) and MetaMorph version 4.6.5 software (Universal Imaging, Downingtown, PA).

2.8. Statistical Analysis. Statistical analysis was performed using SPSS13.0 software. Experiments were repeated at least three times with consistent results. Normally distributed data were represented as mean \pm SEM. Paired $t$-test was used to examine the significance of differences among groups (GraphPad Prism 5.0). A probability value with ${ }^{*} P<0.05$ and ${ }^{* *} P<0.01$ was considered to be statistically significant.

\section{Results}

3.1. Curcumin Has a Role in the Regulation of Proliferation and Apoptosis of MDA.MB231 Breast Cancer Cells. In order to assess the effects of curcumin on proliferation and apoptosis of MBA.MB231 cells, we performed in vitro assays. Results from wound-healing and MTT tests showed that curcumin inhibits the migration of breast cancer cells at $48 \mathrm{~h}$ (Figures 1(a), 1(b), and 1(c)). By performing flow cytometry analysis, we demonstrated that curcumin regulates the apoptosis process of MBA.MB231 cells (Figure 1(d)). This result was also confirmed by Western blotting analysis of p53 expression (Figures 1(e) and 1(f)). Taken together, our results suggest that curcumin inhibits proliferation and enhanced apoptosis of MDA.MB231 breast cancer cells.

3.2. Curcumin Inhibits the Tumour Growth and Microvessel Formation in Heterotopic Mouse Model of Breast Cancer. We generated a mouse model of breast cancer, to study the role of curcumin on tumor growth and angiogenesis. When tumors reached $\sim 30-60 \mathrm{~mm}^{3}, 16$ mice were randomized into two groups: 8 controls (normal diet) and 8 curcumintreated. The treatment with curcumin started after tumor cell's implantation and continued up to 6 weeks. Results obtained by detection of mice body indicated that curcumin has no toxicity effect on mice. Tumor volumes decreased significantly after 3 weeks of curcumin treatment until 6 weeks as compared to controls (Figures 2(a) and 2(b)). In order to assess if curcumin inhibits microvessel formation in breast tumors, fluorescein-isothiocyanate- (FITC-) dextran was injected into the tail veins of mice. Our data demonstrate that curcumin reduces microvessel formation in tumours of treated mice with respect to controls (Figure 2(c)).

\subsection{Effects of Curcumin on NF- $\kappa B$ Activation in Heterotopic} Breast Tumors. It has been reported that curcumin potentiates the antitumor activity of paclitaxel in breast cancer by influencing the expression of NF- $\kappa \mathrm{B}$-regulated gene products 


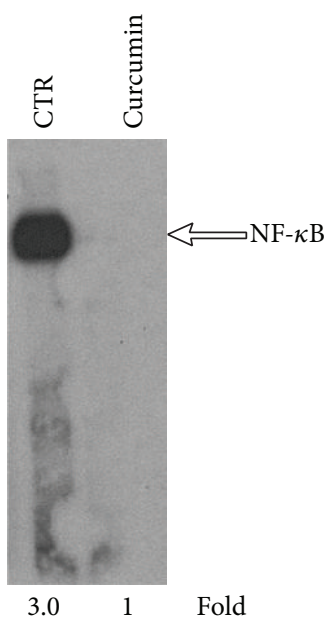

(a)
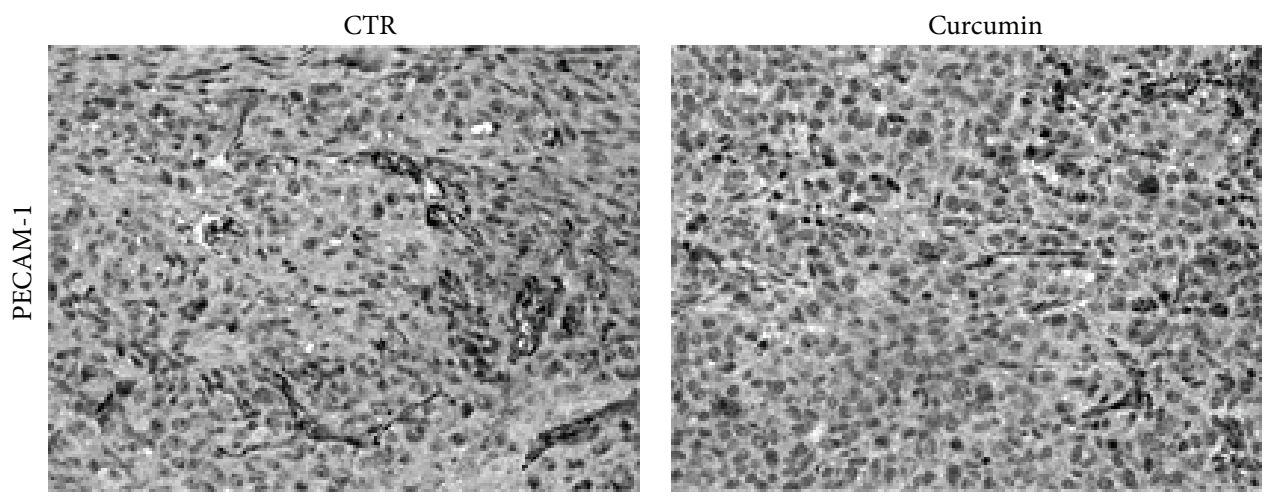

(b)
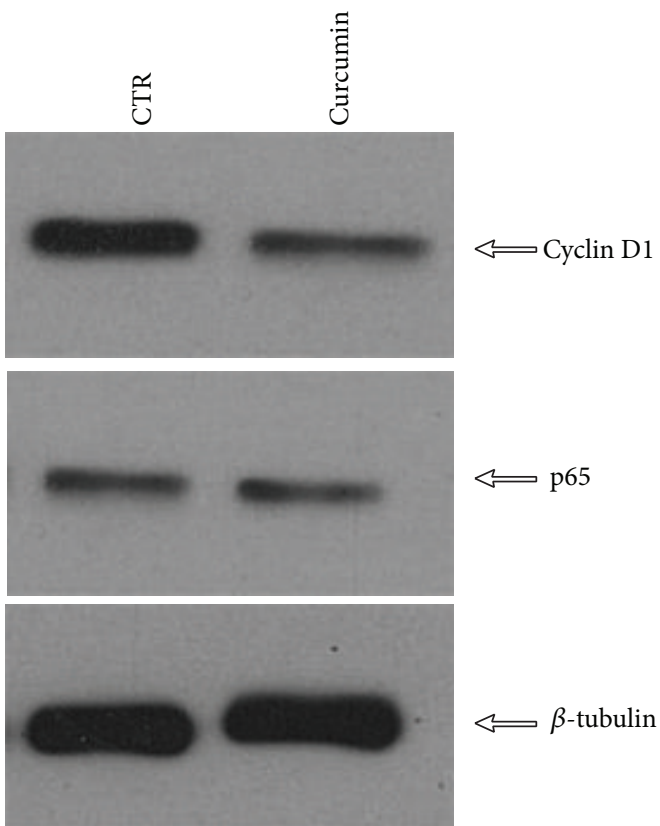

(c)

FIgURE 3: Curcumin inhibits NF- $\kappa$ B activation and downregulates NF- $\kappa$ B-regulated gene products in breast tumors. (a) EMSA assay performed on tumor tissue samples showed the inhibition of NF- $\kappa$ B by curcumin. (b) Immunohistochemistry for PECAM-1 showed the inhibition of PECAM-1 expression in curcumin-treated group, compared to controls. (c) Western blot showing that curcumin inhibits the expression of NF- $\kappa$ B-dependent gene products, cyclin D1, and p-65 in breast tumor tissues. Samples from three animals in each group were analyzed and representative data are shown. $\beta$-tubulin was used as loading control.

[34]; for this reason we performed DNA binding assay on tumors of control and curcumin-treated mice. Our results showed that curcumin inhibits the activation of NF- $\kappa \mathrm{B}$ (Figure 3(a), lane 2). We also tested the effects of curcumin on the expression of NF- $\kappa \mathrm{B}$-regulated gene products such as cyclin D1, p65, and PECAM-1, by immunohistochemistry and Western blotting analysis. Our results showed that in tumours of curcumin-treated group, there were significant reductions in the expression of PECAM-1, cyclin D1, and p65 compared to the control group (Figures 3(b) and 3(c)). These data showed that curcumin is able to influence the expression of NF- $\kappa \mathrm{B}$-regulated gene products in mouse model of breast cancer.

\section{Discussion}

In this paper we dissected the role of curcumin in tumor growth and angiogenesis in mouse model of human breast cancer. In vitro data allowed us to demonstrate that curcumin regulates the proliferation and the apoptosis of MDA.MB231 cells. To test the effects of curcumin in heterotopic mouse models of breast cancer, we used complete feed for mice 
with curcumin $0,6 \%$. Based on mice diet tables reported in literature [35], we have estimated, approximatively, that mice assumed $25 \mathrm{mg} /$ die of curcumin. We decided to use this system also to overcome the problem of low in vivo bioavailability of curcumin [36]. In vivo data showed that tumors of mice treated with curcumin were smaller than those observed in controls, indicating that curcumin has an antitumor effect on breast cancer cells. We showed that curcumin inhibits tumor growth and angiogenesis through the modulation of NF- $\kappa \mathrm{B}$ pathway. Since curcumin is very well tolerated in human subjects and is assumed by food, our data demonstrated that curcumin could be considered an alternative nontoxic agent in the treatment of triple negative breast cancer.

\section{Conflict of Interests}

The authors declare that there is no conflict of interests regarding the publication of this paper.

\section{Acknowledgments}

The authors thank Massimiliano Spinelli, for kindly help in providing informatics assistance. The authors also thank Dr. Daniele Di Napoli for animal care. This work was supported by the $5 \mathrm{x}$ mille and current research programs of Institute National of Tumors, IRCCS “Foundation G. Pascale”, Naples (Italy).

\section{References}

[1] M.-T. Park, M.-J. Kim, Y.-H. Kang et al., "Phytosphingosine in combination with ionizing radiation enhances apoptotic cell death in radiation-resistant cancer cells through ROSdependent and -independent AIF release," Blood, vol. 105, no. 4, pp. 1724-1733, 2005.

[2] N. Eckstein, "Platinum resistance in breast and ovarian cancer cell lines," Journal of Experimental and Clinical Cancer Research, vol. 30, no. 1, article 91, 2011.

[3] Z. Jiang, J. Guo, J. Shen, M. Jin, S. Xie, and L. Wang, "The role of estrogen receptor alpha in mediating chemoresistance in breast cancer cells," Journal of Experimental and Clinical Cancer Research, vol. 31, no. 1, article 42, 2012.

[4] C. Marquette and L. Nabell, "Chemotherapy-resistant metastatic breast cancer," Current Treatment Options in Oncology, vol. 13, no. 2, pp. 263-275, 2012.

[5] G. Yan, K. Graham, and S. Lanza-Jacoby, "Curcumin enhances the anticancer effects of trichostatin a in breast cancer cells," Molecular Carcinogenesis, vol. 52, no. 5, pp. 404-411, 2013.

[6] A. B. Kunnumakkara, P. Anand, and B. B. Aggarwal, "Curcumin inhibits proliferation, invasion, angiogenesis and metastasis of different cancers through interaction with multiple cell signaling proteins," Cancer Letters, vol. 269, no. 2, pp. 199-225, 2008.

[7] S. M. Gao, J. J. Yang, C. Q. Chen et al., "Pure curcumin decreases the expression of WT1 by upregulation of miR-15a and miR-16-1 in leukemic cells," Journal of Experimental and Clinical Cancer Research, vol. 31, article 27, 2012.

[8] C. A. Reddy, V. Somepalli, T. Golakoti et al., "Mitochondrialtargeted curcuminoids: a strategy to enhance bioavailability and anticancer efficacy of curcumin," PLoS ONE, vol. 9, no. 3, Article ID e89351, 2014.

[9] G. Ji, J. Yang, and J. Chen, "Preparation of novel curcuminloaded multifunctional nanodroplets for combining ultrasonic development and targeted chemotherapy," International Journal of Pharmaceutics, vol. 466, no. 1-2, pp. 314-320, 2014.

[10] M. Farazuddin, B. Dua, Q. Zia, A. A. Khan, B. Joshi, and M. Owais, "Chemotherapeutic potential of curcumin-bearing microcells against hepatocellular carcinoma in model animals," International Journal of Nanomedicine, vol. 9, pp. 1139-1152, 2014.

[11] Y. Zhan, Y. Chen, R. Liu, H. Zhang, and Y. Zhang, "Potentiation of paclitaxel activity by curcumin in human breast cancer cell by modulating apoptosis and inhibiting EGFR signaling," Archives of Pharmacal Research, vol. 37, no. 8, pp. 1086-1095, 2014.

[12] Y. Yu, X. Zhang, and L. Qiu, "The anti-tumor efficacy of curcumin when delivered by size/charge-changing multistage polymeric micelles based on amphiphilic poly $(\beta$-amino ester $)$ derivates," Biomaterials, vol. 35, no. 10, pp. 3467-3479, 2014.

[13] D. Liu and Z. Chen, "The effect of curcumin on breast cancer cells," Journal of Breast Cancer, vol. 16, no. 2, pp. 133-137, 2013.

[14] A. Garufi, D. Trisciuoglio, M. Porru et al., "A fluorescent curcumin-based $\mathrm{Zn}(\mathrm{II})$-complex reactivates mutant $(\mathrm{R} 175 \mathrm{H}$ and $\mathrm{R} 273 \mathrm{H}$ ) p53 in cancer cells," Journal of Experimental and Clinical Cancer Research, vol. 32, no. 1, article 72, 2013.

[15] S. Bimonte, A. Barbieri, G. Palma, A. Luciano, D. Rea, and C. Arra, "Curcumin inhibits tumor growth and angiogenesis in an orthotopic mouse model of human pancreatic cancer," BioMed Research International, vol. 2013, Article ID 810423, 8 pages, 2013.

[16] T.-L. Chiu and C.-C. Su, "Curcumin inhibits proliferation and migration by increasing the $\mathrm{Bax}$ to $\mathrm{Bcl}-2$ ratio and decreasing NF-kappaBp65 expression in breast cancer MDA-MB-231 cells," International Journal of Molecular Medicine, vol. 23, no. 4, pp. 469-475, 2009.

[17] Q. Liu, W. T. Y. Loo, S. C. W. Sze, and Y. Tong, "Curcumin inhibits cell proliferation of MDA-MB-231 and BT- 483 breast cancer cells mediated by down-regulation of $\mathrm{NF} \kappa \mathrm{B}$, cyclinD and MMP-1 transcription," Phytomedicine, vol. 16, no. 10, pp. 916922, 2009.

[18] H. Zong, F. Wang, Q.-X. Fan, and L.-X. Wang, "Curcumin inhibits metastatic progression of breast cancer cell through suppression of urokinase-type plasminogen activator by NFkappa B signaling pathways," Molecular Biology Reports, vol. 39, no. 4, pp. 4803-4808, 2012.

[19] H. J. Kang, S. H. Lee, J. E. Price, and L. S. Kim, "Curcumin suppresses the paclitaxel-induced nuclear factor-B in breast cancer cells and potentiates the growth inhibitory effect of paclitaxel in a breast cancer nude mice model," Breast Journal, vol. 15, no. 3, pp. 223-229, 2009.

[20] M. Narasimhan and S. Ammanamanchi, "Curcumin blocks RON tyrosine kinase-mediated invasion of breast carcinoma cells," Cancer Research, vol. 68, no. 13, pp. 5185-5192, 2008.

[21] H.-W. Lai, S.-Y. Chien, S.-J. Kuo et al., "The potential utility of curcumin in the treatment of HER-2-overexpressed breast cancer: an in vitro and in vivo comparison study with herceptin," Evidence-Based Complementary and Alternative Medicine, vol. 2012, Article ID 486568, 12 pages, 2012.

[22] G. Chakraborty, S. Jain, S. Kale et al., "Curcumin suppresses breast tumor angiogenesis by abrogating osteopontin-induced VEGF expression," Molecular Medicine Reports, vol. 1, no. 5, pp. 641-646, 2008. 
[23] C. E. Carroll, M. R. Ellersieck, and S. M. Hyder, "Curcumin inhibits MPA-induced secretion of VEGF from T47-D human breast cancer cells," Menopause, vol. 15, no. 3, pp. 570-574, 2008.

[24] Y. H. Soung and J. Chung, "Curcumin inhibition of the functional interaction between integrin alpha6beta 4 and the epidermal growth factor receptor," Molecular Cancer Therapeutics, vol. 10, no. 5, pp. 883-891, 2011.

[25] S. S. Chung and J. V. Vadgama, "Curcumin and epigallocatechin gallate inhibit the cancer stem cell phenotype via downregulation of STAT3-NFאB signaling," Anticancer Research, vol. 35, no. 1, pp. 39-46, 2015.

[26] T. Jia, L. Zhang, Y. Duan et al., "The differential susceptibilities of MCF-7 and MDA-MB-231 cells to the cytotoxic effects of curcumin are associated with the PI3K/Akt-SKP2-Cip/Kips pathway," Cancer Cell International, vol. 14, article 126, 2014.

[27] M. Yamaguchi, S. Zhu, S. Zhang et al., "Curcumin analogue UBS109 prevents bone loss in breast cancer bone metastasis mouse model: involvement in osteoblastogenesis and osteoclastogenesis," Cell and Tissue Research, vol. 357, no. 1, pp. 245-252, 2014.

[28] Z. D. Lv, X. P. Liu, W. J. Zhao et al., "Curcumin induces apoptosis in breast cancer cells and inhibits tumor growth in vitro and in vivo," International Journal of Clinical and Experimental Pathology, vol. 7, no. 6, pp. 2818-2824, 2014.

[29] D. V. Singh, S. Agarwal, P. Singh, M. M. Godbole, and K. Misra, "Curcumin conjugates induce apoptosis via a mitochondrion dependent pathway in MCF-7 and MDA-MB-231 cell lines," Asian Pacific Journal of Cancer Prevention, vol. 14, no. 10, pp. 5797-5804, 2013.

[30] N. Mo, Z.-Q. Li, J. Li, and Y.-D. Cao, "Curcumin inhibits TGFbetal-induced MMP-9 and invasion through ERK and smad signaling in breast cancer MDA-MB-231 cells," Asian Pacific Journal of Cancer Prevention, vol. 13, no. 11, pp. 5709-5714, 2012.

[31] N. Cine, P. Limtrakul, D. Sunnetci, B. Nagy, and H. Savli, "Effects of curcumin on global gene expression profiles in the highly invasive human breast carcinoma cell line MDA-MB 231: a gene network-based microarray analysis," Experimental and Therapeutic Medicine, vol. 5, no. 1, pp. 23-27, 2013.

[32] X. D. Sun, X. E. Liu, and D. S. Huang, "Curcumin induces apoptosis of triple-negative breast cancer cells by inhibition of EGFR expression," Molecular Medicine Reports, vol. 6, no. 6, pp. 1267-1270, 2012.

[33] A. B. Kunnumakkara, S. Guha, S. Krishnan, P. Diagaradjane, J. Gelovani, and B. B. Aggarwal, "Curcumin potentiates antitumor activity of gemcitabine in an orthotopic model of pancreatic cancer through suppression of proliferation, angiogenesis, and inhibition of nuclear factor- $\kappa \mathrm{B}$-regulated gene products," Cancer Research, vol. 67, no. 8, pp. 3853-3861, 2007.

[34] B. B. Aggarwal, S. Shishodia, Y. Takada et al., "Curcumin suppresses the paclitaxel-induced nuclear factor-kappaB pathway in breast cancer cells and inhibits lung metastasis of human breast cancer in nude mice," Clinical Cancer Research, vol. 11, no. 20, pp. 7490-7498, 2005.

[35] H. J. Lewerenz, "J. E. Harkness und J. E. Wagner: the biology and medicine of rabbits and rodents. 152 Seiten. Lea and Febinger, Philadelphia 1977. Preis: 8,- \$, Food/Nahrung, vol. 23, no. 1, p. 99, 1979.

[36] P. Anand, A. B. Kunnumakkara, R. A. Newman, and B. B. Aggarwal, "Bioavailability of curcumin: problems and promises," Molecular Pharmaceutics, vol. 4, no. 6, pp. 807-818, 2007. 


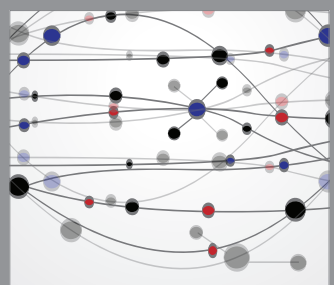

The Scientific World Journal
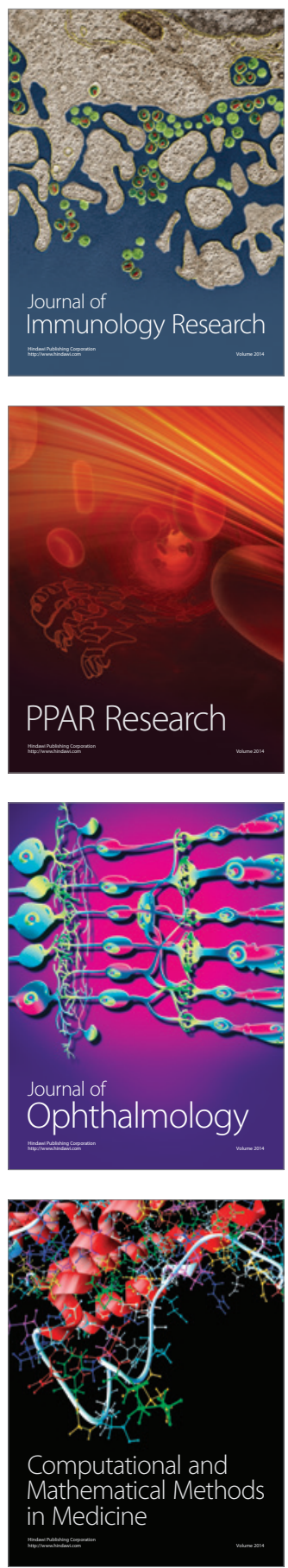

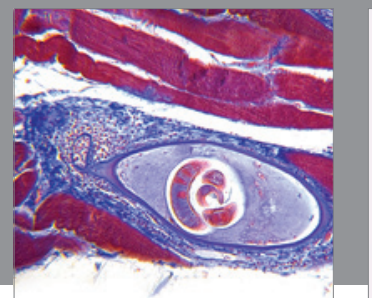

Gastroenterology

Research and Practice
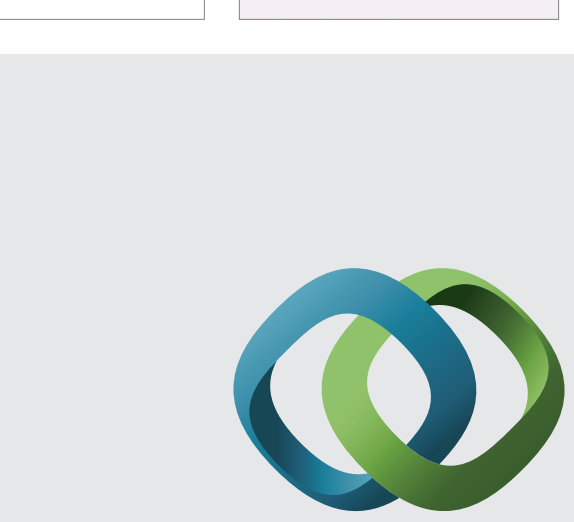

\section{Hindawi}

Submit your manuscripts at

http://www.hindawi.com
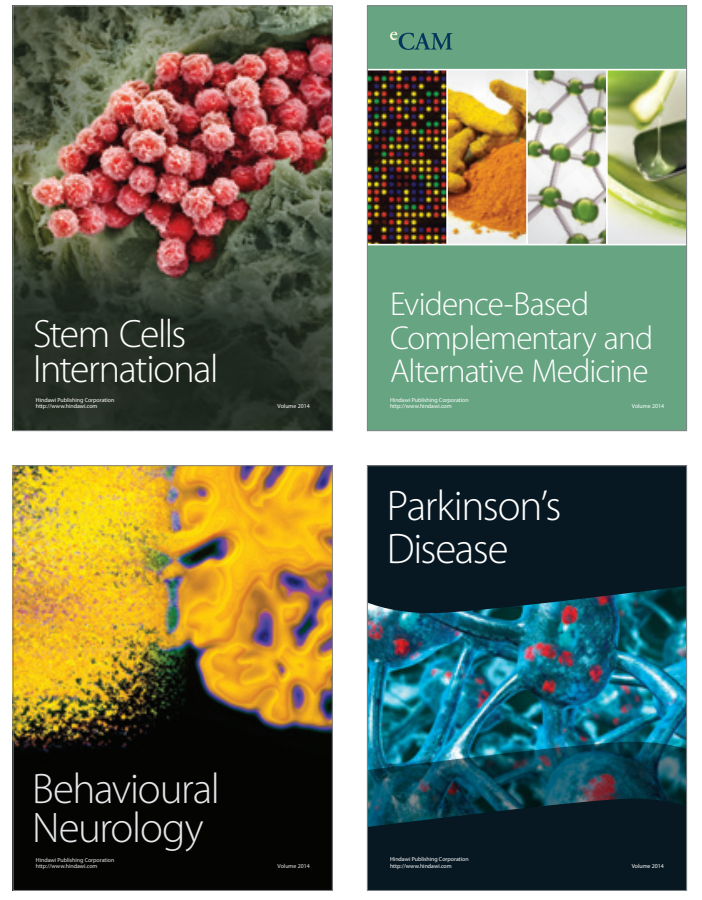
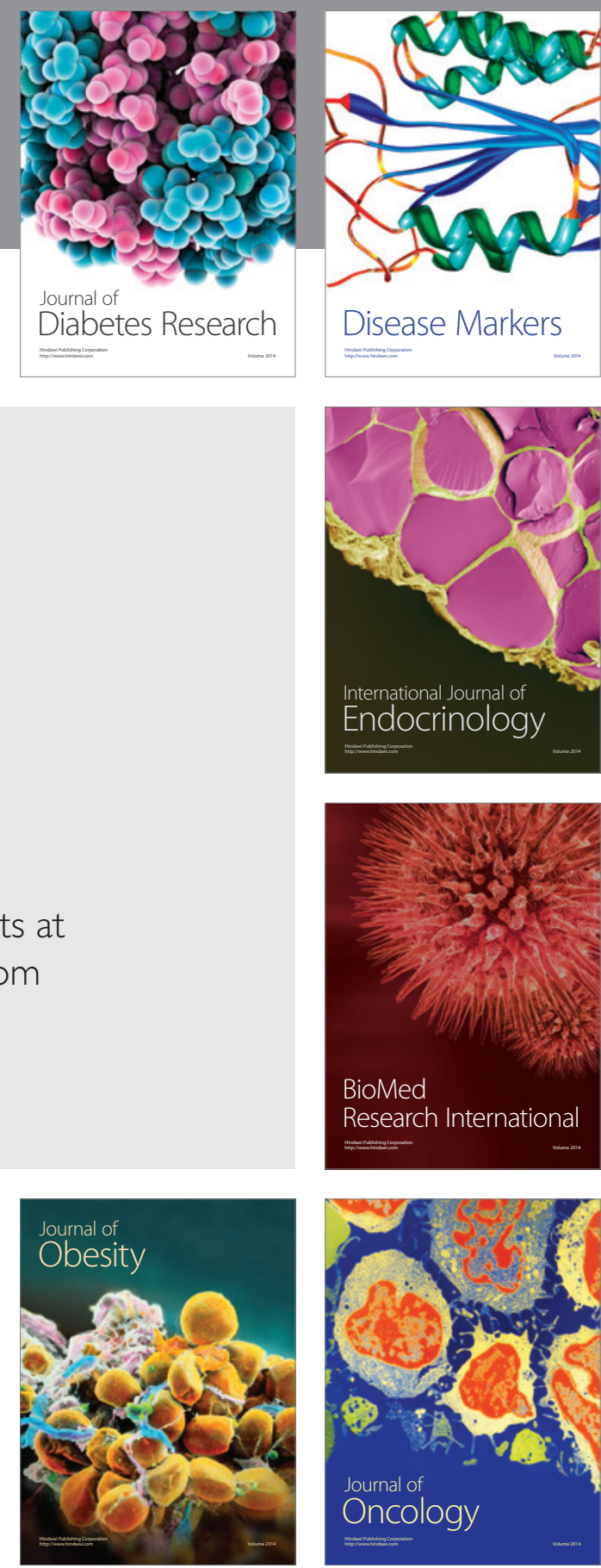

Disease Markers
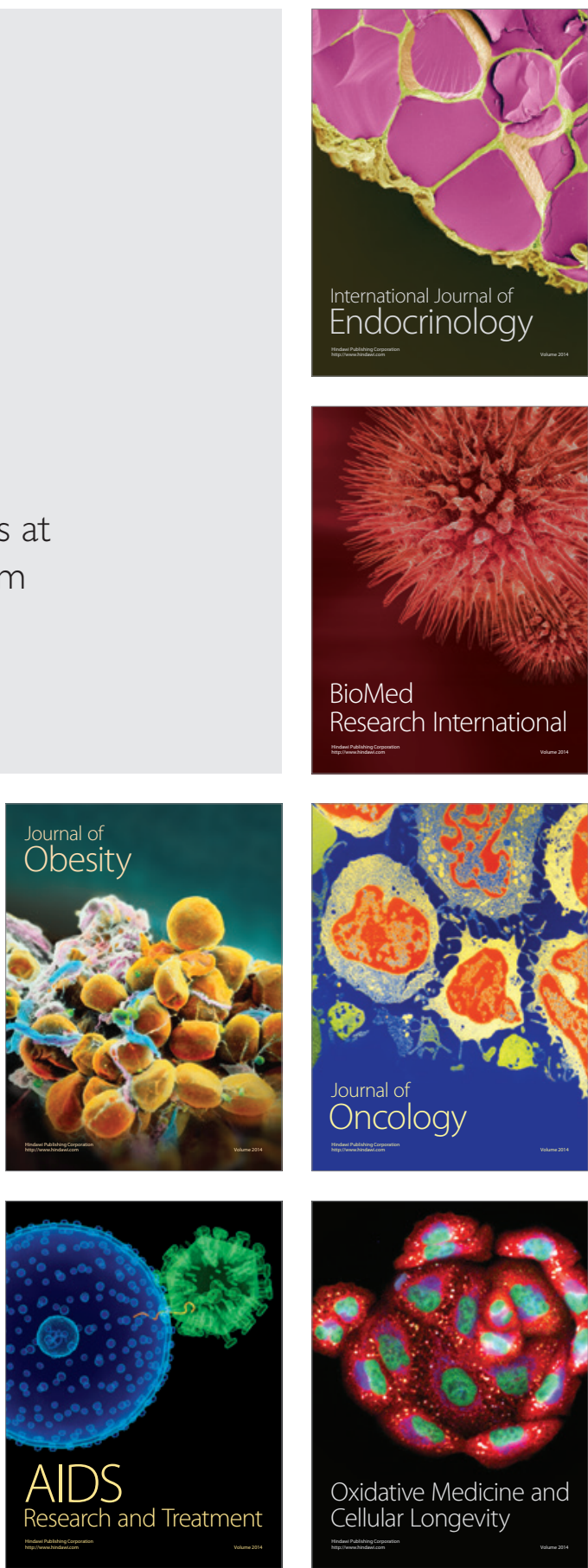